\title{
Natural variants of human p85 $\alpha$ phosphoinositide 3-kinase in severe insulin resistance: a novel variant with impaired insulin-stimulated lipid kinase activity
}

\author{
K.C.R.Baynes ${ }^{1}$, C.A.Beeton ${ }^{2}$, G.Panayotou ${ }^{3}$, R.Stein ${ }^{3}$, M.Soos ${ }^{1}$, T.Hansen ${ }^{4}$, H.Simpson ${ }^{5}$, S.O'Rahilly ${ }^{1}$, \\ P. R.Shepherd ${ }^{2}$, J.P. Whitehead ${ }^{1}$ \\ ${ }^{1}$ Departments of Medicine and Clinical Biochemistry, University of Cambridge, UK \\ 2 Department of Biochemistry, University College London, UK \\ ${ }^{3}$ Ludwig Institute of Cancer Research, London, UK \\ ${ }^{4}$ Steno Diabetes Center, Gentofte, Denmark \\ ${ }^{5}$ Diabetes Centre, Royal Berkshire Hospital, Reading, UK
}

\section{Abstract}

Aims/hypothesis. Phosphoinositide 3-kinase (PI 3K) plays a central part in the mediation of insulin-stimulated glucose disposal. No genetic studies of this enzyme in human syndromes of severe insulin resistance have been previously reported.

Methods. Phosphoinositide 3-kinase p85a regulatory subunit cDNA was examined in 20 subjects with syndromes of severe insulin resistance by single strand conformational polymorphism and restriction fragment length polymorphism analyses. Insulin-stimulated phosphoinositide 3-kinase activity and recruitment into phosphotyrosine complexes of variants of $p 85 \alpha$ were studied in transiently transfected HEK293 cells. Phosphopeptide binding characteristics of wild-type and mutant p85a-GST fusion proteins were examined by surface plasmon resonance.

Results. The common p85a variant, $\mathrm{Met}^{326} \mathrm{I} 1 \mathrm{e}$, was identified in 9 of the 20 subjects. Functional studies of the $\mathrm{Met}^{326}$ Ile variant showed it to have equivalent insulin-stimulated lipid kinase activity and phosphotyrosine recruitment as wild-type p85 $\alpha$. A novel heterozygous mutation, $\mathrm{Arg}^{409} \mathrm{Gln}$, was detected in one subject. Within the proband's family, carriers of the mutation had a higher median fasting plasma insulin $(218 \mathrm{pmol} / \mathrm{l})$ compared with wild-type relatives $(72 \mathrm{~mol} / \mathrm{l})(n=8$ subjects, $p=0.06)$. The $\mathrm{Arg}^{409} \mathrm{Gln}$ p $85 \alpha$ subunit was associated with lower insulin-stimulated phosphoinositide 3-kinase activity compared with wild-type (mean reduction $15 \%, \mathrm{p}<0.05$, $n=5)$. The recruitment of $\mathrm{Arg}^{409} \mathrm{Gln} \mathrm{p} 85 \alpha$ into phosphotyrosine complexes was not significantly impaired. GST fusion proteins of wild-type and mutant p85 $\alpha$ showed identical binding to phosphopeptides in surface plasmon resonance studies.

Conclusion/interpretation. Mutations in p85a are uncommon in subjects with syndromes of severe insulin resistance. The $\mathrm{Met}^{326} \mathrm{Ile} \mathrm{p} 85 \alpha$ variant appears to have no functional effect on the insulin-stimulated phosphoinositide 3-kinase activity. The impaired phosphoinositide 3-kinase activity of the $\mathrm{Arg}^{409} \mathrm{Gln}$ mutant suggests that it could contribute to the insulin resistance seen in this family. [Diabetologia (2000) 43: 321-331]

Keywords Keywords Genetics, insulin signalling, phosphatidylinositol 3-kinase.
Received: 21 July 1999 and in revised form: 19 October 1999

Corresponding author: Professor S. O'Rahilly, Department of Medicine, Box 157, Level 5, Addenbrooke's Hospital, Hills Road, Cambridge CB2 2QR, UK

Abbreviations: EBVL, Epstein-Barr virus transformed lymphocytes; GST, glutathione S-transferase; IPTG, isopropyl- $\beta$ D-thiogalactoside; PDK-1, phosphatidylinositol [3, 4, 5] P3-dependent kinase-1, PI 3K phosphoinositide 3-kinase; PI P3, phosphatidylinositol $[3,4,5]$ phosphate; $\mathrm{PKB}$, protein kinase $\mathrm{B}$; $\mathrm{SH} 2$ domain, homology domain; SSCP, single-strand conformational polymorphism; TLC thin layer chromatography.
Severe insulin resistance is found in a heterogeneous group of uncommon disorders characterised by acanthosis nigricans, impaired glucose tolerance or diabetes mellitus and in women, features of hyperandrogenism such as oligomenorrhoea and hirsutism [1-3]. The mechanisms underlying severe insulin resistance in human disease remain poorly understood, but mutations in the insulin receptor gene or autoantibodies to the insulin receptor are responsible in only a small minority of cases [4-6]. The increasing knowledge of the complexity of intracellular insulin signalling path- 


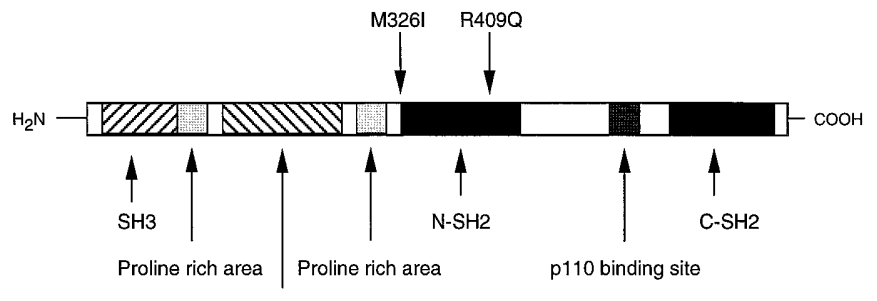

BCR Homology

Fig. 1. Domain structure of $\mathrm{p} 85 \alpha$ regulatory subunit of PI $3 \mathrm{~K}$ showing the positions of the two variants identified

ways has opened up a large number of candidate genes potentially responsible for cases of genetically determined insulin resistance [7].

Insulin activates the intrinsic tyrosine kinase of its receptor which phosphorylates YXXM amino acid sequence motifs in a number of proteins, primarily the insulin receptor substrates (IRS) $[8,9]$ which then recruit a variety of proteins through their $\mathrm{SH} 2$ domains. The class $I_{a}$ phosphoinositide 3-kinases (PI $3 \mathrm{~K})$ are recruited in this way [10]. Insulin-stimulated activation of PI $3 \mathrm{~K}$ results in the generation of phosphorylated lipid products from membrane-bound substrates which act as intracellular second messengers [11]. Activation of PI $3 \mathrm{~K}$ precedes a number of important signalling events including stimulation of phosphatidylinositol $[3,4,5] \quad \mathrm{P}_{3}$-dependent kinase-1 (PDK-1) dependent kinase-1 (PDK-1), protein kinase B, p70 s6 kinase, GLUT4 vesicle translocation to the plasma membrane and inhibition of glycogen synthase kinase-3. Moreover, PI $3 \mathrm{~K}$ is necessary, if not sufficient, for the insulin-stimulated increase in glucose uptake and glycogen synthesis in insulin-sensitive tissues $[12,13]$.

The involvement of PI $3 \mathrm{~K}$ in mediating downstream metabolic effects of insulin led us to postulate that defects in insulin-stimulated PI 3K activity might explain severe insulin resistance in some people. To date, no systematic study of the PI $3 \mathrm{~K}$ genes in the syndromes of severe insulin resistance has been undertaken. Impaired PI 3K activation in cultured dermal fibroblasts in a small number of subjects with the pseudoacromegalic phenotype of severe insulin resistance has, however, recently been described [14-16] indicating the possibility that primary defects in PI $3 \mathrm{~K}$ genes could be found.

The class $I_{a} 3 \mathrm{~K}$ activated by insulin consist of a $110000 \mathrm{M}_{\mathrm{r}}$ catalytic subunit (p110) tightly linked to an $85000 \mathrm{M}_{\mathrm{r}}$ regulatory subunit (p85) [11]. A number of forms of the regulatory subunit exist, but all of these contain two SH2 domains, which mediate the recruitment of the PI $3 \mathrm{~K}$ heterodimer to signalling complexes containing tyrosine phosphorylated YXXM motifs. Two highly homologous full-length class $\mathrm{I}_{\mathrm{a}}$ PI $3 \mathrm{~K}$ regulatory subunit genes have been identified, these being $\mathrm{p} 85 \alpha$ and $\mathrm{p} 85 \beta$ [17-21]. Both $\mathrm{p} 85 \alpha$ and $\mathrm{p} 85 \beta$ contain two C-terminal region $\mathrm{SH} 2$ domains which are separated by the catalytic subunit binding domain (Fig.1). Also common to both isoforms and situated in the N-terminal region are an SH3 domain, a BCR (Breakpoint-Cluster Region) homology domain and two short proline-rich domains (Fig.1). A third regulatory subunit gene termed $\mathrm{p} 55 \gamma$ has recently been identified which encodes a shorter gene product lacking these N-terminal domains [22]. Additionally, two major splice variants of the p85 $\alpha$ gene have been described which result in truncated proteins also lacking the $\mathrm{N}$-terminal domains [23-26]. We have previously established that p85 $\alpha$ and its splice variants are all expressed and regulated by insulin in human muscle which is a major site of insulin-mediated glucose disposal [27]. The importance of these splice variants has been shown recently in a p85a gene knockout mouse in which the fulllength $\mathrm{p} 85 \alpha$ gene product is deleted, but the splice variants are still expressed [28]. These p85 $\alpha$ knockout mice show major changes in their profile of glucose metabolism indicating that $\mathrm{p} 85 \alpha$ and its splice variants play a crucial part in insulin-mediated glucose disposal in vivo. Although sequence variants of p85a have been described in studies of human cohorts, no functional studies of natural variants have been reported. We describe here the results of a search for genetic variation in the p $85 \alpha$ regulatory subunit in subjects with severe insulin resistance and the biochemical analysis of two amino acid variants of this protein.

\section{Materials and methods}

Clinical subjects. Subjects had all been referred to Addenbrooke's hospital with a diagnosis of severe insulin resistance (Table 1) which was confirmed, where possible, by pronounced hyperinsulinaemia during a standard $75-\mathrm{g}$ oral glucose tolerance test. Measurements of specific insulin were made by a chemiluminescent immunoassay (Access Immunoassay System, Beckman Instruments, High Wycombe, UK.

Total RNA extraction and $c D N A$ synthesis. Dermal fibroblasts derived from subject skin biopsies were grown to confluence in DMEM (Sigma, Poole, UK) containing $10 \%$ fetal bovine serum, $25 \mathrm{~mol} / \mathrm{l}$ glucose, $2 \mathrm{~mol} / \mathrm{l}$ glutamine, 100 units penicillin $\mathrm{ml} /$ and $100 \mathrm{mg}$ streptomycin $\mathrm{ml} / \mathrm{l}$ and lysed directly in TRIzol reagent (GibcoBRL, Paisley, UK). Lymphocytes derived from subject wholeblood samples were transformed using EpsteinBarr virus to create independent cell lines (EBVLs). These were grown in RPMI-1640 medium (Sigma) containing additions as above until visibly clumping. Cells in suspension were then pelleted by centrifugation at $2000 \mathrm{~g}$ for $5 \mathrm{~min}$ and resuspended in TRIzol reagent. Total RNA from subject relatives was extracted from buffy coat preparations of venous blood samples. Total RNA was reverse transcribed into cDNA using random hexamer oligonucleotides as primers (Promega, Southampton, UK).

Polymerase chain reaction. We amplified $200 \mathrm{ng}$ cDNA by the polymerase chain reaction (PCR) method using 1 unit of Taq DNA polymerase (Bioline, London, UK), $0.3 \mu \mathrm{mol} / 1$ primers 
Table 1. Clinical characteristics of study subjects

\begin{tabular}{lllclc}
\hline Number & Diagnosis & Sex & $\begin{array}{l}\text { Fasting } \\
\text { insulin } \\
\text { pmol/l }\end{array}$ & $\begin{array}{l}\text { 2-h } \\
\text { insulin } \\
\text { pmol/l }\end{array}$ & $\begin{array}{c}\text { Fasting } \\
\text { glucose } \\
\text { mmol/l }\end{array}$ \\
\hline 1 & PA & F & 287 & 2,555 & 6.6 \\
2 & PA & F & 106 & NA & 14.8 \\
3 & PA & M & 6,540 & NA & 6.2 \\
4 & VIR DM & F & NA & NA & NA \\
5 & Type A & F & 90 & 6,830 & 5.4 \\
6 & Type A & F & 736 & NA & 5.9 \\
7 & Lipoatrophy & M & 5,944 & 8,080 & 9.9 \\
8 & Type A & F & 101 & 6,237 & 5.4 \\
9 & Type A & M & 449 & 3,515 & 5.4 \\
10 & Type A & F & 267 & 1,473 & 4.2 \\
11 & Type A & F & 248 & NA & 4.4 \\
12 & Type A & F & 525 & 1,009 & 4.4 \\
13 & Type A & F & 202 & 4,354 & 5.8 \\
14 & Type A & F & 259 & 3,505 & 4.5 \\
15 & Lipoatrophy & F & 500 & 2,000 & 4.9 \\
16 & Type A & F & 357 & 1,330 & 7.9 \\
17 & Type A & F & 180 & NA & 11.6 \\
18 & Type A & F & 212 & 2,268 & 4.7 \\
19 & Type A & F & 703 & NA & 4.6 \\
20 & Lipoatrophy & F & 310 & 3,105 & 6.0 \\
\hline
\end{tabular}

\section{PA Pseudo-acromegaly}

Type A Type A insulin resistance syndrome

VIR DM Very insulin resistant Type II diabetes mellitus

Lipoatrophy Lipodystrophic syndromes

NA Data not available

(Genosys, Cambridge, UK) and 0.75 or $1.5 \mathrm{~mol} / \mathrm{l}$ using $40 \mathrm{cy}$ cles of denaturing $94^{\circ} \mathrm{C} \times 60 \mathrm{~s}$, annealing $52^{\circ} \mathrm{C}$ or $54^{\circ} \mathrm{C} \times 60 \mathrm{~s}$ and extending $72^{\circ} \mathrm{C} \times 60 \mathrm{~s}$ with a final extension at $72^{\circ} \mathrm{C}$ for 7 min.

Single-strand conformational polymorphism (SSCP) and heteroduplex analysis. We amplified p85 $\alpha$ cDNA by PCR in 12 overlapping segments of approximately $250 \mathrm{bp}$ by using primer pairs specific to the human p85 $\alpha$ cDNA sequence (Table 2). Radiolabelled PCR products were generated by including 0.04-0.07 $\mathrm{MBq} \alpha^{32} \mathrm{P}$ dCTP (Amersham Pharmacia Biotech, Little Chalfont, UK) in the PCR mixture. These were diluted in formamide loading buffer to a uniform concentration and run on non-denaturing gels under two conditions: firstly, mutation detection enhancement (MDE) gel (Flowgen, Ashby-dela-Zouch, UK) run at room temperature at $8 \mathrm{~W}$ for $6 \mathrm{~h}$ and secondly, $6 \%$ polyacrylamide gel run at $80^{\circ} \mathrm{C}$ at $40 \mathrm{~W}$ for $4 \mathrm{~h}$. Gels were dried, exposed to autoradiography film (Biomax MR, Kodak, Anachem, Luton, UK) for 24-48 h and then developed.

DNA sequencing. Polymerase chain reaction products of interest were generated using one biotinylated primer and the PCR product isolated using streptavidin-coated magnetic beads (Dynabeads, Dynal, UK). Single-strand DNA was then sequenced directly using ${ }^{35} \mathrm{~S}$-labelled nucleotides by Sanger dideoxy methodology (USB Sequenase 2.0 kit, Amersham Pharmacia Biotech).

Expression vector construction. Plasmids containing the wildtype bovine $\mathrm{p} 85 \alpha$ coding sequence alone (pBS.p85 $\alpha$ and pcDNA3.p85 $\alpha$ ) or with an N-terminal GST tag (pGEX2T.p85 $\alpha$ ) were a gift from M.D. Waterfield. A C-terminal Myc epitope tag was inserted into p $85 \alpha$ by PCR. The $\mathrm{Arg}^{409} \mathrm{Gln}$ (R409Q) variant was introduced into pBS.p85aMyc by PCR of a Xho I/Sal I fragment and then sub-cloned into the pGEX2T · p85 $\alpha$ GST-fusion protein expression vector (Amersham Pharmacia Biotech) through an Nsi I fragment. The $\mathrm{Met}^{326}$ Ile variant was introduced into pGEX2T.p85 $\alpha$ by PCR of a Pst I/Sal I fragment and then sub-cloned into pcDNA3.p85aMyc. The plasmid pcDNA3.p85 $\alpha$ MycR409Q was generated by sub-cloning a $B a m H \mathrm{I} / X b a$ I fragment from pBS.p $85 \alpha-$ MycR409Q into the pcDNA3 backbone (Invitrogen, Leek, The Netherlands). The human $\mathrm{p} 110 \alpha$ coding sequence (a gift from M.D. Waterfield) was inserted into pcDNA3 and a C-terminal FLAG epitope tag was added using PCR (pcDNA3.p110a.FLAG).

Transient transfection. We grew HEK293 cells to $60 \%$ confluence in $60 \mathrm{~cm}^{2}$ dishes and transfected with calcium phosphate using $8 \mu \mathrm{g}$ pcDNA3.p85 $\alpha$ Myc and $6 \mu \mathrm{g}$ pcDNA3.p110 $\alpha$ FLAG or empty vector. Transfection efficiencies by this technique were estimated by transfection with pTracer (Invitrogen) a vector which results in overexpression of green fluorescent protein. Cell counting using a fluorescence microscope (Carl Zeiss microscope, Welwyn Garden City, UK) showed that transfection efficiencies ranged from $20-25 \%$. Cells were harvested $36 \mathrm{~h}$ after transfection. All cells were serum-starved for $16 \mathrm{~h}$ and then stimulated with $100 \mathrm{nmol} / \mathrm{l}$ insulin for $10 \mathrm{~min}$. Cells were lysed in $1 \mathrm{ml}$ PI $3 \mathrm{~K}$ lysis buffer $(137 \mathrm{mmol} / \mathrm{l} \mathrm{NaCl}$, $2.7 \mathrm{mmol} / 1 \mathrm{KCl} \mathrm{MgCl}, 0.5 \mathrm{mmol} / 1 \mathrm{Na}_{3} \mathrm{VO}_{4}, 1 \% \mathrm{v} / \mathrm{v}$ Nonidet $\mathrm{P} 40,10 \% \mathrm{w} / \mathrm{v}$ glycerol, $20 \mathrm{mmol} / \mathrm{l}$ TRIS $\mathrm{pH} 8.0$ at $4{ }^{\circ} \mathrm{C}$, $21 \mu \mathrm{mol} / \mathrm{l}$ leupeptin, $0.2 \mathrm{mmol}$ phenylmethylsulphonylfluoride). Insoluble material was removed by centrifugation at $10000 \mathrm{~g}$ for $5 \mathrm{~min}$.

Immunoprecipitation and immunoblotting. Cleared cell lysate $(160 \mu \mathrm{l})$ was incubated at $4{ }^{\circ} \mathrm{C}$ for $90 \mathrm{~min}$ on a rotating wheel with $1.5 \mu \mathrm{l}$ of mouse monoclonal antiphosphotyrosine antibody (PY99, Santa Cruz Biotechnology, Autogen-Bioclear, Calne, UK). Then $2.5 \mathrm{mg}$ of rehydrated Protein A-agarose beads (Sigma) were added, incubated for a further $60 \mathrm{~min}$ and washed three times. Protein samples were boiled for $5 \mathrm{~min}$ in Laemmli sample buffer, resolved by SDS-PAGE and transferred to Immobilon-P polyvinylidene fluoride membranes (Millipore, Bedford, Ma., USA) by semi-dry blotting. The membranes were blocked in $1 \%$ bovine serum albumin (BSA) in phosphate-buffered saline (PBS)-Tween $0.1 \% \mathrm{v} / \mathrm{v}$ (Sigma) incubated with primary antibody, washed with PBSTween, incubated with secondary antibody and finally washed in PBS-Tween. The Myc epitope was detected with 9E10 primary antibody (a gift from G. Evan) and $\mathrm{I}^{125}$-labelled secondary antibody, the membranes were exposed to a phosphorimager screen overnight and quantified using a Fujix BAS 2000 phosphorimager (Raytek Scientific, Sheffield, UK). The FLAG epitope was detected with polyclonal primary antibody (Santa Cruz Biotechnology) and horseradish peroxidaselinked secondary antibody and enhanced chemiluminescence reagent (Amersham Pharmacia Biotech), then membranes were exposed to autoradiography film and bands were quantified.

Phosphoinositide 3-kinase assays. The technique for the measurement of PI 3K activity was adapted from a previously published technique [29]. Immunoprecipitates from $160 \mu \mathrm{l}$ cleared cell lysate were collected and washed three times in PI 3K lysis buffer, two times in buffer $2(0.5 \mathrm{~mol} / 1 \mathrm{LiCl}, 0.1 \mathrm{~mol} / 1 \mathrm{TRIS}-$ $\mathrm{HCl} \mathrm{pH} 8.0$ at $\left.4{ }^{\circ} \mathrm{C}\right)$, once in buffer $3(0.15 \mathrm{~mol} / \mathrm{l} \mathrm{NaCl}, 1 \mathrm{~mol} / \mathrm{l}$ EDTA, $10 \mathrm{~mol} / 1 \mathrm{TRIS}-\mathrm{HCl} \mathrm{pH} 7.6$ at $4{ }^{\circ} \mathrm{C}$ ) and once in buffer 4 (20 mol/l HEPES, $1 \mathrm{~mol} / \mathrm{l}$ dithiothreitol, $5 \mathrm{~mol} / \mathrm{l} \mathrm{MgCl}_{2} \mathrm{pH}$ 7.6 at $4{ }^{\circ} \mathrm{C}$ ). The immunoprecipitates were then resuspended in $40 \mu \mathrm{l}$ kinase assay buffer $(20 \mathrm{~mol} / \mathrm{l} \beta$-glycerophosphate $\mathrm{pH}$ 
Table 2. Sequences of oligonucleotide primers used for PCR amplification of human p85 $\alpha$ PI 3K cDNA for SSCP

\begin{tabular}{llll}
\hline Primer pair & Forward primer $5^{\prime}$ to $3^{\prime}$ & Reverse primer $5^{\prime}$ to $3^{\prime}$ & $\begin{array}{l}\text { PCR product } \\
\text { size }(\mathrm{bp})\end{array}$ \\
\hline 1 & CAACCAGGCTCAACTGTTGC & ACCAGCCAATTTCTTCAGGC \\
2 & GCTCTTGGATTCAGTGATGG & TTGATAAGAAGAGGCGGGGC \\
3 & GATCTTGCAGAGCAGTTTGC & GGTAAGTCCAGGAGATAGCG & 286 \\
4 & GTGCACGTTTTGCTGACGC & TGCTGGAGGTTTGAGAGAGC \\
5 & TCATCAGTATTGGCTTACGC & GTTATTCATACCGTTGTTGGC \\
6 & CCTCCTAAACCACCAAAACC & GGTTAATGGGTCAGAGAAGC & 232 \\
7 & CTCTTACACTAAGGAAAGGGG & TGACAACTTGATCCTGTTGG & 273 \\
8 & CTCTAGCTCAGTATAATCCC & AAATGCTTCAATAGCTGTCC & 206 \\
9 & GAAGAATATACCCGCACATCC & ATTTCTCGATACTCAGCTGC & 226 \\
10 & GACAGTAGAAGAAGATTGGAAG & TGCTTCCAACATTCCATGTC & 284 \\
11 & GAAGACCAATATTCACTGGTGG & CACCAGTTCTTTCAGAGAGC & 267 \\
p55a & AACTGGCTATGGCTTTGCCG & GATGGCTTCGTTTCTGCAGC & 275 \\
\hline
\end{tabular}

7.2 at $4{ }^{\circ} \mathrm{C}, 5 \mathrm{~mol} / \mathrm{l}$ sodium pyrophosphate, $30 \mathrm{mmol} / \mathrm{l} \mathrm{NaCl}$, $1 \mathrm{mmol} / 1$ dithiothreitol), $20 \mu \mathrm{l}$ lipid mix [freshly prepared by vortexing a $1.67 \mathrm{mg}$ aliquot of phosphatidylinositol (Lipid Products, South Nutfield, UK) in $560 \mu$ l kinase assay buffer containing $1 \% \mathrm{w} / \mathrm{v}$ cholic acid] and added and samples incubated at $37^{\circ} \mathrm{C}$ for $5 \mathrm{~min} 0.02 \mathrm{MBq}{ }^{32} \mathrm{P}$-ATP in $40 \mu 1$ reaction mix ( $3 \mathrm{~mol} / \mathrm{l}$ cold ATP, $7.6 \mathrm{~mol} / 1 \mathrm{MgCl}_{2}$ in kinase assay buffer) were then added and incubated for a further $15 \mathrm{~min}$ before terminating the lipid kinase reaction with $0.45 \mathrm{ml} \mathrm{CHCl}_{3} / \mathrm{MeOH}$ $1: 2 \mathrm{v} / \mathrm{v}$. The phospholipids were extracted by two washes in

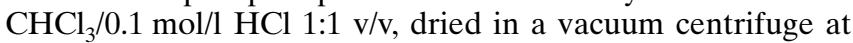
$1000 \mathrm{~g}$ for $30 \mathrm{~min}$ and the residue dissolved in $35 \mu \mathrm{l} \mathrm{CHCl}_{3} /$ $\mathrm{MeOH} / 0.1 \mathrm{~mol} / \mathrm{l} \mathrm{HCl} 200: 100: 1 \mathrm{v} / \mathrm{v}$ and separated by thin layer chromatography (TLC) as described elsewhere [30]. The dried TLC plates were exposed on a phosphorimager screen for $30 \mathrm{~min}$ and the amount of phosphatidylinositol 3-phosphate produced was quantified using a Fujix BAS 2000 phosphorimager.

Glutathione-S-transferase-fusion protein expression. Glutathione-S-transferase (GST)-fusion proteins were induced by isopropyl- $\beta$-D-thiogalactoside (IPTG) in E. coli and purified from bacterial lysates by glutathione sepharaose columns (Amersham Pharmacia Biotech).

Phosphopeptide binding studies. A biotinylated-tyrosine-phosphorylated $17 \mathrm{mer}$ peptide corresponding to the PDGF $\beta$ receptor Y751 SH2 domain binding site (DMSKDESV$D^{*}$ YVPMLDMK) was immobilised on an avidin-coated surface plasmon resonance biosensor chip (BIAcore, Uppsala, Sweden). Binding of the p85 $\alpha$ GST fusion proteins to this biosensor surface was completed by the addition of either monophosphorylated non-biotinylated $17 \mathrm{mer}$ peptide or a diphosphorylated non-biotinylated 19mer peptide (GG*YMDMSKDESSVD*YVPML) containing 2 YXXM motifs corresponding to the Y740 and Y751 SH2 domain binding sites of the PDGF $\beta$ receptor [31].

\section{Results}

Molecular scanning. The $\mathrm{p} 85 \alpha$ coding sequence was examined in 20 subjects ( 17 female, 3 male) with features of severe insulin resistance using revers-transcription-PCR-single-strand conformational polymorphism (RT-PCR-SSCP) and heteroduplex analy- sis. All SSCP and heteroduplex variants were further studied by direct nucleotide sequencing. Three variants were detected in this cohort which on DNA sequencing showed two silent polymorphisms (TAC $\rightarrow$ TAT at nucleotide 261 in seven subjects, ATT $\rightarrow$ ATC at nucleotide 663 in two subjects) and a single-point mutation (CGG $\rightarrow$ CAG at codon 409) which resulted in a novel heterozygous missense amino acid change $\mathrm{Arg}^{409} \mathrm{Gln}$ in one person (Fig.1). Analysis of the p55a splice variant of p85a, which contains a unique 32 amino acid $\mathrm{N}$-terminal extension, showed no additional SSCP variants. In agreement with others we also found that all cDNA samples sequenced at amino acid residue 330 coded for Asp suggesting that there is an error in the published sequence of p85a [32]. Also of note was the absence of mutations in the p85 $\alpha$ gene in the pseudoacromegalic patients whom we have previously reported to have impaired insulin-stimulated PI 3K activity in their cultured dermal fibroblasts [15].

The subject carrying the $\mathrm{Arg}^{409} \mathrm{Gln}$ missense variant was a 23-year-old Caucasian female with features of the Type A syndrome who began to develop hirsutism, oligomenorrhoea and impaired glucose tolerance in her late teenage years (subject 14 in Table 1). She had a history of acanthosis nigricans since infancy. Biochemical evaluation during 2-h 75-g OGTT showed increased plasma specific insulin both fasting $259 \mathrm{pmol} / \mathrm{l}(95 \%$ reference range $<80 \mathrm{pmol} / \mathrm{l})$ and at $2 \mathrm{~h} 3505 \mathrm{pmol} / \mathrm{l}$ with corresponding plasma glucoses 4.5 and $10.3 \mathrm{mmol} / \mathrm{l}$. This subject had previously been studied for the presence of insulin receptor gene mutations and none were found.

Family and population genetic studies. Because the $\mathrm{Arg}^{409} \mathrm{Gln}$ variant causes the loss of an Msp I restriction site, available members of the proband's family were genotyped by restriction fragment length polymorphism (RFLP) analysis and evaluated biochemically by fasting plasma insulin and glucose measurements. Genotype results obtained from RT-PCR of 

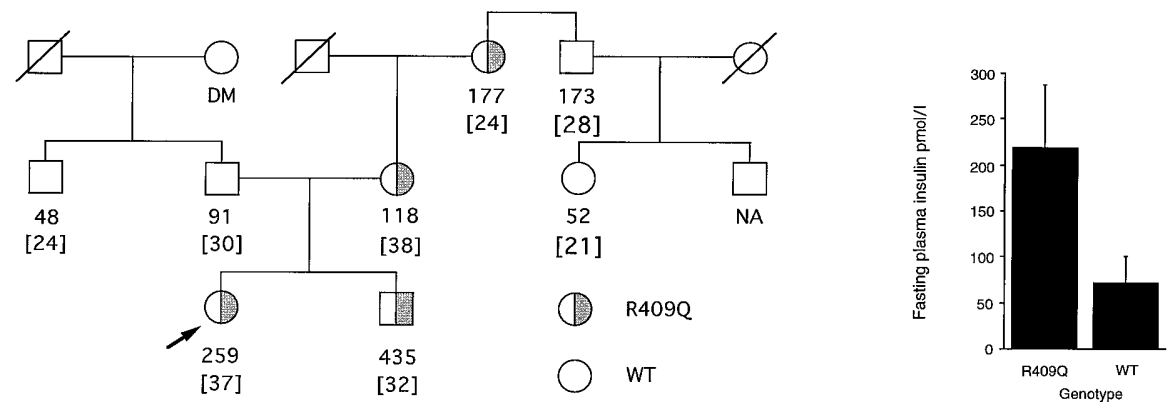

Fig. 2. Family tree of $\mathrm{Arg}^{409} \mathrm{Gln}$ proband. Upper numerals indicate fasting insulin (pmol/l) and lower numerals body mass index $\left[\mathrm{kg} / \mathrm{m}^{2}\right]$, where information is available. DM, Type II diabetes mellitus; NA, not available. Inset graph shows median fasting insulin values \pm SEM for $\mathrm{Arg}^{409}$ Gln carriers vs wildtype subjects $\left(\mathrm{Arg}^{409} \mathrm{Gln} 218 \mathrm{pmol} / \mathrm{l} \pm 69\right.$; WT $72 \mathrm{pmol} / \mathrm{l} \pm 29$; $p=0.06$, Mann-Whitney, two-tailed)

total RNA extracted from buffy coat preparations were confirmed by an independent PCR using genomic DNA and a different set of primers. The heterozygous $\mathrm{Arg}^{409} \mathrm{Gln}$ variant was inherited through the maternal line (Fig.2). The proband's brother, who was also heterozygous for the $\mathrm{Arg}^{409} \mathrm{Gln}$ variant, was known to have had acanthosis nigricans since childhood. Individual fasting plasma insulin concentrations in all four carriers were above the normal range with a median plasma insulin in $\mathrm{Arg}^{409} \mathrm{Gln}$ heterozygotes of $218 \mathrm{pmol} / \mathrm{l} \pm 69 \quad(n=4$, medians \pm SEM) compared with $72 \mathrm{pmol} / 1 \pm 29(n=4)$ in relatives who were wild-type at that site $(\mathrm{p}=0.06$, MannWhitney: two-tailed). All the relatives studied had normal fasting plasma glucose values (range $4.5-5.6 \mathrm{mmol} / \mathrm{l})$.

The RFLP analysis of 271 Danish subjects (136 with Type II (non-insulin-dependant) diabetes mellitus, 135 non-diabetic) found no subjects carrying the $\mathrm{Arg}^{409} \mathrm{Gln}$ variant. Similarly this variant was not found in 50 non-diabetic middle-aged UK Caucasians with fasting hyperinsulinaemia (range 91-316 pmol/l) from the Isle of Ely study [33] thus confirming that this is not a common variant.

Our SSCP study did not detect the common $\mathrm{p} 85 \alpha$ polymorphism $\mathrm{Met}^{326} \mathrm{Ile}$ previously reported in a Danish cohort. A specific RFLP assay for this variant [34] showed that the Met $^{326}$ Ile polymorphism was present in our severe insulin-resistant cohort at an allelic frequency of $25 \%$ (30 WT alleles, $10 \mathrm{Met}^{326} \mathrm{I} 1 \mathrm{e}$ alleles) representing eight heterozygotes and one homozygote. This reflects the less than $100 \%$ sensitivity of the SSCP technique for mutation detection. Pertinently, the person heterozygous for the $\mathrm{Arg}^{409} \mathrm{Gln}$ variant did not carry the $\mathrm{Met}^{326}$ Ile variant.

\section{Functional studies}

Effects of p85a variants on insulin-stimulated PI $3 \mathrm{~K}$ enzymatic activity. To examine the effects of the variant p85a. sequences on insulin-stimulated PI 3K activity HEK293 cells were transfected with wild-type or valiant Myc-tagged p $85 \alpha$ constructs and FLAGtagged wild-type p110 $\alpha$. Cells were stimulated with $100 \mathrm{nmol} / \mathrm{l}$ insulin for $10 \mathrm{~min}$ and the PI 3K enzymatic activity present in antiphosphotyrosine immunoprecipitates was measured. Insulin-stimulated PI 3K activity in antiphosphotyrosine immunoprecipitates from mock transfected cells were approximately $20 \%$ of that in cells transfected with wild-type p85a and p110 $\alpha$ (data not shown) Phosphoinositide 3-kinase activity was consistently and significantly lower in $\mathrm{Arg}^{409} \mathrm{Gln}$ than in wild-type transfections ( $76 \pm 4 \%$ vs $100 \pm 5 \%, p<0.01, n=5$ experiments) (Fig. 3). In contrast, cells transfected with the $\mathrm{Met}^{326}$ I1e adaptor subunit were indistinguishable from wild type $(95 \pm 11 \%$ vs $100 \pm 5 \%)$ (Fig. 3 ). The presence of a Myc tag on the p85 constructs allowed variability in the expression of the $\mathrm{p} 85 \alpha$ variants to be taken into account. A significant difference in PI 3K activation remained after correcting the PI $3 \mathrm{~K}$ activities for the amount of Myc tag detected in the antiphosphotyrosine immunoprecipitates by western blotting (WT $100 \% \pm 5 \mathrm{vs} \mathrm{Arg}^{409} \mathrm{Gln} 85 \% \pm 4, n=5$, $p<0.05$ ) (Fig. 3). Correction for p85a expression in the immunoprecipitates did not alter the results with the $\mathrm{Met}^{326} \mathrm{I} 1 \mathrm{e}$ variant which remained similar to wild type (Fig. 3).

The major role of $p 85 \alpha$ is to facilitate recruitment of p110 $\alpha$ into signalling complexes so we also analysed the amount of $\mathrm{p} 110 \alpha$-FLAG present in the antiphosphotyrosine immunoprecipitates. This showed a similar pattern to that observed for $\mathrm{p} 85 \alpha$ with the PI $3 \mathrm{~K}$ activity corrected for FLAG tag being significantly lower for $\mathrm{Arg}^{409} \mathrm{Gln}$ (WT $100 \% \pm 5$ vs $\mathrm{Arg}^{409} \mathrm{Gln}$ $84 \% \pm 5, \quad p<0.05$; WT $100 \% \quad$ vs, Met $^{326}$ Ile $114 \% \pm 10, p=\mathrm{NS}$; (Fig. 3 ).

Effects of p $85 \alpha$ variants on intrinsic activity of PI $3 K$ complexes. To examine whether the variants affected the intrinsic PI $3 \mathrm{~K}$ activity associated with the regulatory subunits HEK293 cells were cotransfected with wild-type and variant Myc-tagged $\mathrm{p} 85 \alpha$ constructs 
A

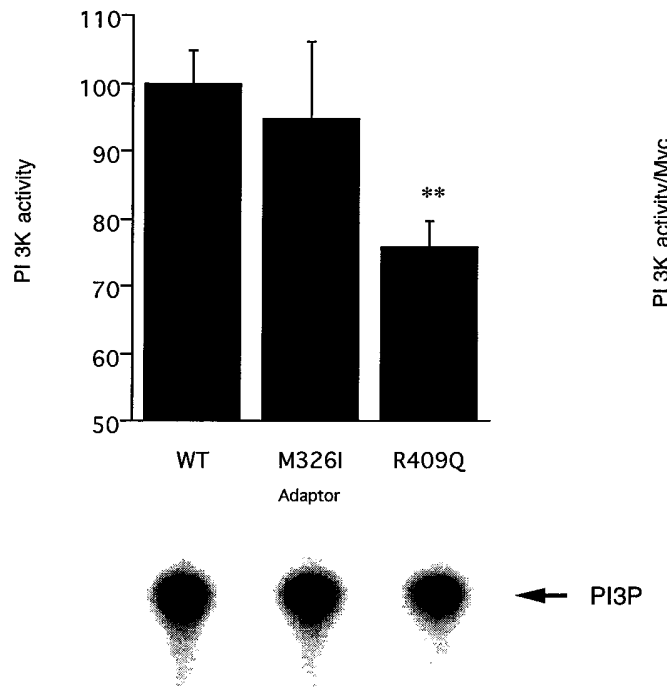

B

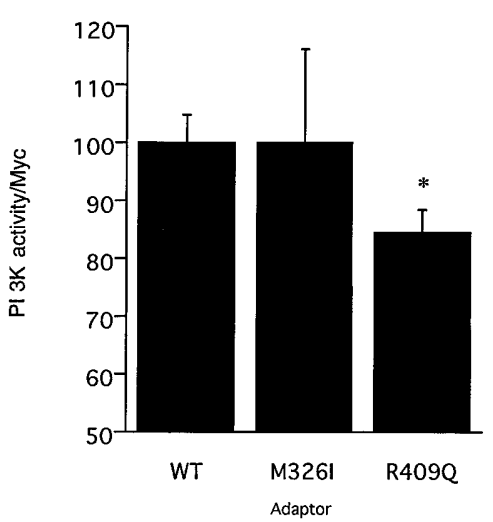

C

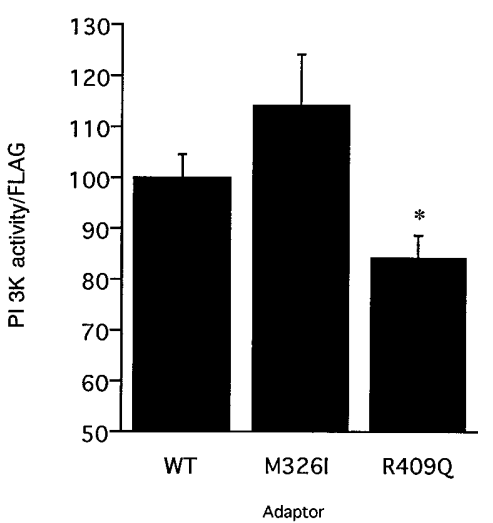

Fig.3 A-C. Phosphoinositide 3-kinase activity in anti-phosphotyrosine immunoprecipitates from HEK293 cells transiently transfected with Myc-tagged p85 $\alpha$ and FLAG-tagged p $110 \alpha$ subunits of PI $3 \mathrm{~K}$, serum-starved overnight and then stimulated with $100 \mathrm{nmol} / \mathrm{l}$ insulin for $10 \mathrm{~min}$. A Uncorrected PI 3K activity expressed as percentage of control. WT $100 \% \pm 5$, $\mathrm{Met}^{326}$ Ile $95 \% \pm 11$, Arg ${ }^{409} \mathrm{Gln} 76 \pm 4$. Data are from five independent experiments. $* * p<0.01$. B Phosphoinositide 3-kinase activity after correction for Myc in immunoprecipitates. WT $100 \% \pm 5$, Met $^{326}$ Ile $97 \% \pm 14$, Arg $^{409}$ Gln $85 \% \pm 4$. Data are from five independent experiments. $* p<0.05$. C Phosphoinositide 3-kinase activity after correction for FLAG in immunoprecipitates. WT $100 \% \pm 5, \mathrm{Met}^{326}$ Ile $114 \% \pm 10, \mathrm{Arg}^{409} \mathrm{Gln}$ $84 \% \pm 5$. Data are from three independent experiments. $* p<0.05$

and FLAG-tagged p110 $\alpha$. We did PI 3K assays on Myc immunoprecipitates from serum-starved cells and intrinsic activity of the expressed forms of PI $3 \mathrm{~K}$ was calculated by correcting the PI $3 \mathrm{~K}$ activity for the amount of Myc in the immunoprecipitates, as assessed by western blotting. These studies showed that the intrinsic activity of the $\mathrm{Met}^{326}$ Ile and $\mathrm{Arg}^{409} \mathrm{Gln}$ adaptor subunits were both equivalent to wild-type p85a (WT $100 \% \pm 12$, Met $^{326} \mathrm{Ile}$ $\left.101 \% \pm 8.3, \quad \mathrm{Arg}^{409} \mathrm{Gln} \quad 98 \% \pm 7 ; \quad n=3, \quad p=\mathrm{NS}\right)$ (Fig. 4).

Effects of $p 85 \alpha$ variants on recruitment to tyrosine phosphorylated signalling intermediates. Because amino acid residue 409 lies within the $\mathrm{N}$-terminal $\mathrm{SH} 2$ domain of $\mathrm{p} 85 \alpha$, variants at this position have the potential to affect binding to phosphotyrosine residues on signalling intermediates. Recruitment of transfected PI 3K subunits into antiphosphotyrosine complexes was assessed by western blotting for Myctagged p85 $\alpha$ and FLAG-tagged p110 $\alpha$ in antiphosp- hotyrosine immunoprecipitates. Insulin-stimulated recruitment of both regulatory and catalytic subunits into phosphotyrosine complexes (Fig. 5). The recruitment of $\mathrm{Met}^{326} \mathrm{Ile}$ and $\mathrm{Arg}^{409} \mathrm{Gln}$ regulatory subunits was not significantly different to wild-type $\mathrm{p} 85 \alpha$ (WT $100 \% \pm 4.7$, Met $^{326}$ Ile $97 \% \pm 13.8$, Arg $^{409}$ Gln $83 \% \pm 7.1 ; n=5, p=\mathrm{NS}$ ) (Fig. 5). Likewise, recruitment of the FLAG-tagged p110 $\alpha$ catalytic subunit of PI 3K into phosphotyrosine complexes was similar for each of the p85 $\alpha$ variants (WT $100 \% \pm 2.5$, Met $^{326} \mathrm{Ile} 98 \% \pm 7, \quad \mathrm{Arg}^{409} \mathrm{Gln} 97 \% \pm 4, \quad n=3$, $p=\mathrm{NS}$ ) (Fig. 5). To rule out the possibility that the reduced PI 3K activity was due to the $\mathrm{Arg}^{409}$ Gln mutant associating less tightly with the catalytic subunit we calculated the ratio of FLAG tag:Myc tag in each of the anti-phosphotyrosine immunoprecipitates and found the ratio was not significantly different between the three regulatory subunit variants (data not shown) suggesting that the adaptor variants did not have altered binding to the p $110 \alpha$ catalytic subunit of PI $3 \mathrm{~K}$.

In vitro binding of Arg409Gln p85a to tyrosine phophorylated proteins. To more closely analyse the binding characteristics of the p85 $\alpha$ variant the binding of wild-type and $\mathrm{Arg}^{409} \mathrm{Gln}$ p85 $\alpha$-GST fusion proteins was compared using a surface plasmon resonance biosensor device. The sensor surface was coated with a tyrosine phosphorylated $17 \mathrm{mer}$ peptide (DMSKDESVD*YVPMLDMK) corresponding to the Y751 site of the PDGF $\beta$ receptor. Binding of the p85a-GST fusion proteins to this sensor surface was completed by the addition of either monophosphorylated $17 \mathrm{mer}$ peptide or a diphosphorylated 19mer peptide (GG*YMDMSKDESSVD*YVPML) corresponding to both the Y740 and Y751 of the PDGF $\beta$ receptor. The half-maximum inhibitory concentrations $\left(\mathrm{IC}_{50}\right)$ derived from the binding curves 


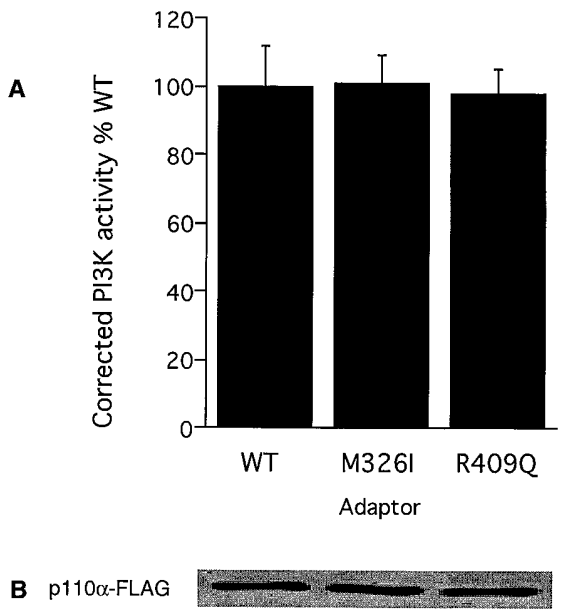

Fig. 4 A, B. Basal PI 3K activity in anti-Myc immunoprecipitates from HEK293 cells transiently transfected with Myc-tagged p $85 \alpha$ and FLAG-tagged p110 $\alpha$ subunits of PI 3K. Cells were serum-starved for $16 \mathrm{~h}$. A Phosphoinositide 3-kinase activity of $\mathrm{p} 85 \alpha$ variants in Myc immunoprecipitates corrected for amount of Myc present expressed as percentage of control. Data are from three independent experiments. WT $100 \% \pm 12$, Met $^{326}$ Ile $101 \% \pm 8$, Arg $^{409}$ Gln $98 \% \pm 7, p=$ NS. B Western blot of p $110 \alpha-F L A G$ in Myc immunoprecipitates

(Fig. 6) were equivalent for both wild-type and Arg ${ }^{409}$ Gln variant $\mathrm{p} 85 \alpha$ (monophosphorylated peptide $\mathrm{IC}_{50}$ WT $14 \mathrm{nmol} / \mathrm{l}$, $\mathrm{Arg}^{409} \mathrm{Gln} 12 \mathrm{nmol} / \mathrm{l}$; diphosphorylated peptide $\mathrm{IC}_{50}$ WT $2 \mathrm{nmol} / \mathrm{l}, \mathrm{Arg}^{409} \mathrm{Gln} 2$ $\mathrm{nmol} / \mathrm{l}$.

\section{Discussion}

A substantial body of biochemical data attests to the importance of PI $3 \mathrm{~K}$ in the mediation of the effects of insulin on cellular glucose metabolism $[12,13]$. Evidence directly implicating dysfunction of this enzyme in human disorders of insulin action has been less readily provable. A reduction in insulin-stimulated PI $3 \mathrm{~K}$ activity in muscle and adipose tissue from insulin-resistant subjects with Type II diabetes or obesity has been reported in a number of studies [35-37]. Impaired insulin-stimulated PI 3K activity in cultured dermal fibroblasts has been reported from subjects with the pseudoacromegalic form of severe insulin resistance suggesting the presence of an intrinsic cellular defect in the PI $3 \mathrm{~K}$ pathway in that rare subtype of severe insulin resistance $[15,16]$.

Until recently there has been little genetic evidence available to confirm the action of this enzyme in the control of whole-body insulin sensitivity in mammals. It was recently reported that mice rendered null for p85 $\alpha$ are, surprisingly, more insulin sensitive than wild-type littermates and have a tendency to develop hypoglycaemia [28]. The experimental strategy employed did not, however, delete the alternatively spliced product of the p85a gene,
A

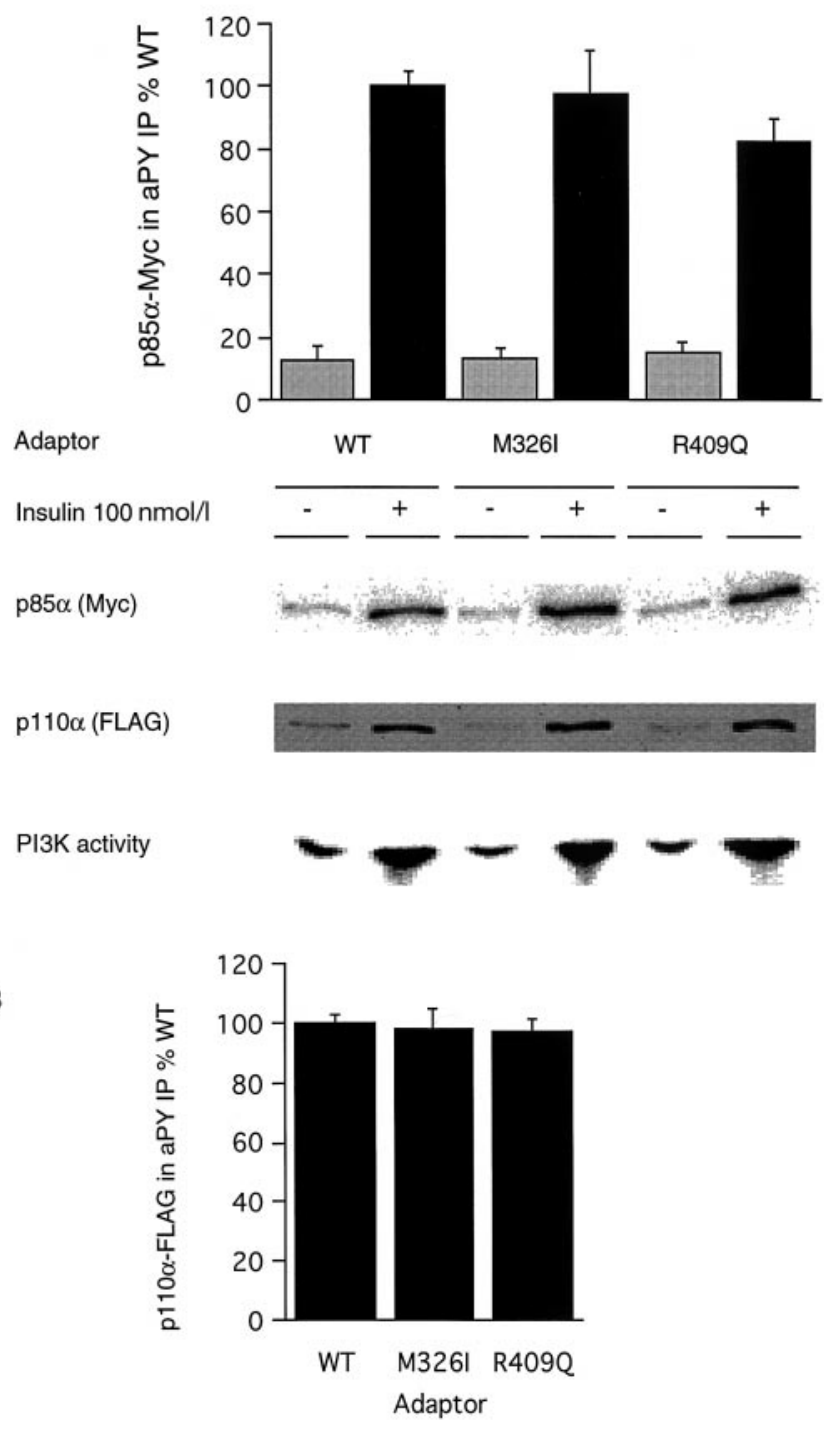

Fig. 5 A, B. Insulin-stimulated recruitment of $p 85 \alpha$ variants and p110 $\alpha$-FLAG into phosphotyrosine complexes. HEK293 cells were transfected with Myc-tagged variant $\mathrm{p} 85 \alpha$ and FLAG-tagged, p110 $\alpha$ subunits of PI 3K, serum-starved overnight and stimulated with $100 \mathrm{nmol} / \mathrm{l}$ insulin for $10 \mathrm{~min}$. A Amounts of Myc-tagged p85a in anti-phosphotyrosine immunoprecipitates expressed as percentage of control. Data are from five independent experiments. WT $100 \% \pm 5$, Met $^{326}$ Ile $97 \% \pm 14, \mathrm{Arg}^{409}$ Gln $83 \% \pm 7, p=$ NS. B Amounts of p110 $\alpha$-FLAG in phosphotyrosine complexes after insulin treatment. Data are from three independent experiments. WT $100 \% \pm 3$, Met $^{326}$ Ile $98 \% \pm 7$, Arg $^{409} \mathrm{Gln} 97 \% \pm 4, p=\mathrm{NS}$

p55 $\alpha$, which was noticeably up-regulated in metabolically active tissues from the knockout mice. As p $55 \alpha$ appears to be capable of coupling to p110 with similar, if not greater, efficiency than p $85 \alpha$, this could explain the enhanced insulin sensitivity seen in these mice.

Several studies examining the $\mathrm{p} 85 \alpha$ gene for mutations in people with Type II diabetes have been re- 
A

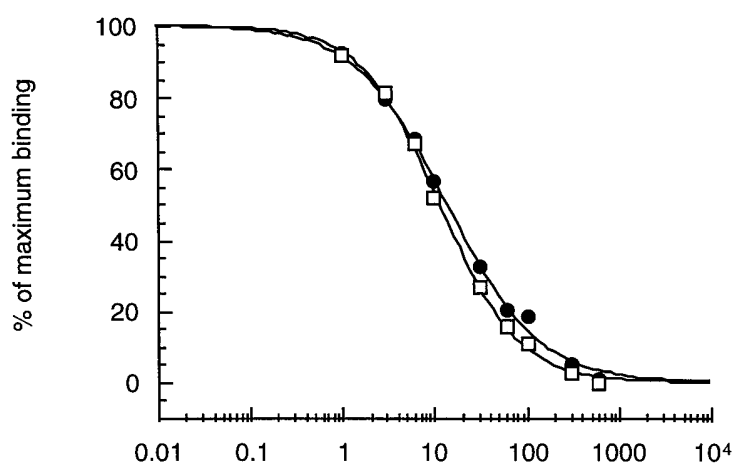

[competing peptide] $\mathrm{nmol} / \mathrm{I}$

B

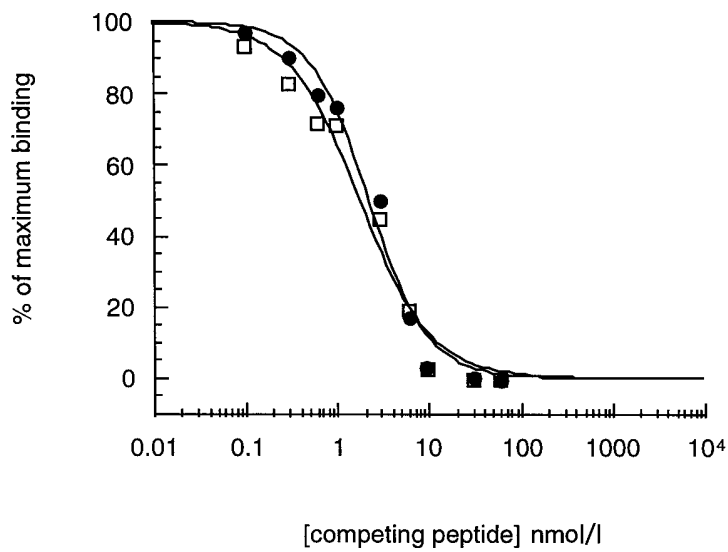

Fig. 6A,B. Binding studies with an optical biosensor. Biotinylated phosphopeptide DMSKDESVD*YVPMLDMK (where * Y indicates phosphotyrosol residues) was captured on immobilised avidin BIAcore sensor chip and binding of wild-type p85 $\alpha$ and $\mathrm{Arg}^{409}$ Gln p85 $\alpha \square$ competed with phosphopeptides in free solution. A Competing with monophosphorylated peptide DMSKDESVD*YVPMLDMK. Half-maximum inhibitory concentrations ( $\mathrm{IC}_{50}$ ) WT p $85 \alpha 14 \mathrm{nmol} / \mathrm{l}, \mathrm{Arg}^{409} \mathrm{Gln}$ p85a $12 \mathrm{nmol} / \mathrm{l}$. B Competing with diphosphorylated peptide GG*YMDMSKDESSVD*YVPML. IC I0 $_{50}$ WT p $85 \alpha 2$ nmol/l, Arg ${ }^{409}$ Gln $\mathrm{p} 85 \alpha 2 \mathrm{nmol} / \mathrm{l}$

ported. The missense polymorphism $\mathrm{Met}^{326} \mathrm{Ile}$ and two common silent polymorphisms [38], which have been previously described, were also found in our patient cohort. Association studies examining the consequences of the $\mathrm{Met}^{326}$ Ile polymorphism have resulted in variable findings; one study has reported that in the homozygous form it is associated with a reduced insulin sensitivity index, glucose disappearance constant and glucose effectiveness [38] whereas another report showed no association with insulin sensitivity [32]. Two reports suggest that the $\mathrm{Met}^{326}$ Ile variant is not associated with Type II diabetes [34, 38], whereas another has reported that in female Pima Indians it is associated with a lower prevalence of Type II diabetes and a higher early phase insulin response [32]. In our group of people with severe insulin resistance we found a similar allelic frequency for the $\mathrm{Met}^{326}$ Ile allele to that reported for Pima Indians (25\%) [32]. The small sample size, however, and mixed racial origin of our group precludes any definite conclusions being drawn from this observation. None of the previous studies have investigated the functional activity of the Met ${ }^{326}$ Ile variant. In detailed functional studies we were not able to discern any functional difference between the $\mathrm{Met}^{326}$ Ile variant and wild type in insulin-stimulated PI 3K activity, association with p110 $\alpha$, intrinsic activity of $\mathrm{p} 85 \alpha-\mathrm{p} 110 \alpha$ complexes or recruitment to tyrosine phosphorylated proteins. Given the variable results of the population association studies and the consistency of our biochemical observations we conclude that this common variant is unlikely to have any major functional relevance.

In one person with severe insulin resistance, we identified the novel heterozygous missense mutation $\mathrm{Arg}^{409} \mathrm{Gln}$. We have established by the study of two separate European populations that this is a rare variant. The possibility that the $\mathrm{Arg}^{409} \mathrm{Gln}$ mutation could have functional relevance is suggested by its location in the N-terminal SH2 domain. Recent studies have shown that the $\mathrm{N}$-terminal SH2 domain has the highest affinity for tyrosine phosphorylated peptides, especially in the context of the truncated $\mathrm{p} 85 \alpha$ splice variants $[31,39]$. The potential functional importance of arginine 409 is suggested by the finding that this residue is conserved between the four published mammalian species (human, bovine, murine, rat); additionally it is conserved between the different adaptor subunits $\mathrm{p} 85 \alpha$ and $\mathrm{p} 85 \beta$, whereas in $\mathrm{p} 55 \gamma$ it is replaced by histidine, a conservative change. Residue 409 is not directly in the phosphotyrosine-binding pocket of $\mathrm{p} 85 \alpha[40]$ so any effect on binding to phosphotyrosine would be by effect on overall conformation. Structural modelling has suggested that the position of the non-conservative variant $\mathrm{Arg}^{409} \mathrm{Gln}$ within the N-terminal SH2 domain might affect the folding of p85 $\alpha$ domains (M. Zvelebil, personal communication).

The proband of our family is a severely insulin-resistant young woman with acanthosis nigricans and hyperandrogenism. Her younger brother is also severely hyperinsulinaemic with acanthosis nigricans developing at a young age. The mutation is present in both subjects. Although the size of the available extended family is too small to provide formal genetic proof of linkage, of particular note is the proband's maternal grandmother whom despite a low body mass index has a greatly increased plasma insulin of $177 \mathrm{pmol} / \mathrm{l}$. The multiple genetic and environmental influences on insulin sensitivity are reflected by the fact that even in families with pathogenic insulin receptor mutations there is enormous interindividual 
variability in severity of hyperinsulinaemia [2]. Accordingly, it is perhaps not surprising that full penetrance of the complete syndrome of severe insulin resistance is not seen in this pedigree.

In transfection studies the $\mathrm{Arg}^{409} \mathrm{Gln}$ mutation was consistently associated with a reduction in insulinstimulated PI 3K activity in anti-phosphotyrosine immunoprecipitates. Further experiments were undertaken to examine possible molecular mechanisms underlying this defect in signal transduction. Recruitment of the mutant p85a into phosphotyrosine-containing signalling complexes such as the insulin receptor substrates was examined. The expression of epitope-tagged forms of wild-type p85 $\alpha$ and the $\mathrm{Arg}^{409} \mathrm{Gln}$ mutant confirm that within intact cells the mutation has no effect on the level of recruitment of the adapter subunit into insulin-induced signalling complexes. In addition, in vitro binding data using the BIAcore surface plasmon resonance system also showed that the $\mathrm{Arg}^{409} \mathrm{Gln}$ mutation had no effect on the binding of p85 $\alpha$ to tyrosine phosphorylated peptides. The use of both monophosphorylated and diphosphorylated peptides in this study excludes the possibility of impaired binding at one or both $\mathrm{SH} 2$ domains due to an effect on the conformation of p85 $\alpha$. It could be argued that the use of phosphopeptides derived from the PDGF $\beta$ receptor rather than from IRS-1 makes this observation less relevant to insulin signalling; it is known, however, that the main determinants of phosphopeptide binding to $\mathrm{SH} 2$ domains in this system are the presence of YXXM motifs which are present in both IRS- 1 and PDGF $\beta$ receptors [31].

This leaves two further ways in which the mutant could be affecting insulin's stimulation of PI 3K activity. The simplest of these is that the catalytic activity of the p85/p110 might be lower when the mutant forms of $p 85 \alpha$ are present in the heterodimer. This is clearly not the case, however, as the epitope tagging has allowed us to directly compare the intrinsic PI $3 \mathrm{~K}$ activity between wild-type and mutant $\mathrm{p} 85 \alpha$ while controlling for the expression of p85 $\alpha$ and $\mathrm{p} 110 \alpha$ present in the immunoprecipitates and these are very similar.

The third possibility relates to the reports that full activation of PI $3 \mathrm{~K}$ catalytic activity requires the binding of phosphotyrosyl residues to both $\mathrm{SH} 2$ domains of $p 85 \alpha$ [41-43]. The molecular basis of this increase in the activity of the catalytic subunit is not known, but could involve a conformational change in the $\mathrm{SH} 2$ domains being transferred by the interSH2 domain to the p110 catalytic subunit. It is therefore possible that mutations in p85 $\alpha$ could affect insulin's ability to activate PI $3 \mathrm{~K}$ through the phosphotyrosine interactions with the $\mathrm{SH} 2$ domains. Indeed, this appears to be the most likely mechanism for the adverse effect of the $\mathrm{Arg}^{409} \mathrm{Gln}$ mutation as its associated enzymatic activity is reduced in the face of similar recruitment to phosphotyrosine-containing signalling intermediates even though the stoichiometry of its physical interaction with $\mathrm{p} 110 \alpha$ seems unimpaired.

How might such an apparently subtle mutation in PI $3 K$ contribute to such a pronounced clinical phenotype? It seems implausible that heterozygosity for a mutant protein that shows only a modest decrease in its in vitro function could result in severe insulin resistance. We have recently discussed how subtle inherited defects in insulin action could lead to a progressive perturbation of glucose homeostasis through the adverse effects on insulin sensitivity of compensatory hyperinsulinaemia [44]. This phenomenon is clearly shown by the progressive development of insulin resistance and diabetes in mice rendered heterozygous null for the insulin-sensitive glucose transporter GLUT4 [45]. Alternatively, the p85 $\alpha$ variant might only result in severe insulin resistance if it is co-inherited with other genetic factors predisposing to insulin resistance. Thus, although heterozygous knock out mice for either the insulin receptor or IRS-1 locus are largely normal, doubly heterozygous mice develop progressive severe insulin resistance and diabetes [46]. Finally, it is probable that we have underestimated the functional defect in PI $3 \mathrm{~K}$ activation in our cellular system as endogenous PI $3 \mathrm{~K}$ is contributing to the overall measured enzymatic activity. Insulin-stimulated PI 3K activity from mock transfected cells was approximately $20 \%$ of cells transfected with wildtype p85 $\alpha$ and $\mathrm{p} 110 \alpha$ (data not shown).

Establishing the underlying basis for defective insulin action in people with clinical syndromes of extreme insulin resistance remains a challenging problem. Apart from insulin receptor gene mutations, monogenic causes of severe insulin resistance have been elusive. Mutations in IRS-1 are uncommon in severe insulin resistance, although one person with a missense mutation in IRS-1 has been described [47]. The Gly ${ }^{972}$ Arg IRS-1 polymorphism has been associated with Type II diabetes $[48,49]$ as have mutations in the PTB domain of IRS-1 [50]. The evidence implicating the $\mathrm{Arg}^{409} \mathrm{Gln}$ mutation in the $\mathrm{p} 85 \alpha$ subunit of PI $3 \mathrm{~K}$ as a causative factor in the severe insulin resistance of the family described in this report is, however, arguably the strongest for the existence of an inherited post-receptor defect in human insulin action.

Acknowledgements. K.C. R. Baynes is supported by a Wellcome Trust Research Training Fellowship and a Sackler Research Studentship. P. R. Shepherd is partly supported by funding from the UK Medical Research Council. We wish to thank Professor M. Waterfield (Ludwig Institute for Cancer Research, London) for generous provision of $\mathrm{p} 85 \alpha$ and $\mathrm{p} 110 \alpha \mathrm{vec}-$ tors, Professor K. Siddle and Dr. B. Urs $\varnothing$ (University of Cambridge) for helpful discussions, Professor N. Hales and Dr. N. Wareham (University of Cambridge) for provision of UK control DNA samples, Dr. O. Pedersen (Steno Diabetes Center, Gentofte, Denmark) for provision of Danish DNA samples and the families involved, for their helpful cooperation. 


\section{References}

1. Tritos NA, Mantzoros CS (1998) Clinical review 97 - Syndromes of severe insulin resistance. J Clin Ednocrinol Metab 83: 3025-3030

2. Moller DE, Flier JS (1991) Insulin resistance - mechanisms, syndromes, and implications. N Eng J Med 325: 938-948

3. Moller DE, O'Rahilly S (1993) Syndromes of severe insulin resistance: clinical and pathophysiological features. In: Moller DE (ed) Insulin resistance. Wiley, Chichester, pp 49-81

4. Taylor SI, Moller DE (1993) Mutations of the insulin receptor gene. In: Moller DE (ed) Insulin resistance. Wiley, Chichester, pp 83-113

5. Krook A, Kumar S, Laing I et al. (1994) Molecular scanning of the insulin receptor gene in syndromes of insulin resistance. Diabetes 43: 357-366

6. Moller DE, Cohen O, Yamaguchi Y et al. (1994) Prevalence of mutations of the insulin receptor gene in subjects with features of the type A syndrome of insulin resistance. Diabetes 43: 247-255

7. Moller DE, Bjorbaek C, Vidal-Puig A (1996) Candidate genes for insulin resistance. Diabetes Care 19: 396-400

8. White W, Kahn CR (1994) The insulin signaling system. J Biol Chem 269: 1-4

9. White MF (1998) The IRS-signalling system: a network of docking proteins that mediate insulin action. Mol Cell Biochem 182: 3-11

10. Ogawa W, Matozaki T, Kasuga M (1998) Role of binding proteins to IRS-1 in insulin signalling. Mol Cell Biochem 182: 13-22

11. Vanhaesbroeck B, Leevers SJ, Panayotou G, Waterfield MD (1997) Phosphoinositide 3-kinases: a conserved family of signal transducers. Trends Biochem Sci 22: 267-272

12. Shepherd PR, Withers DJ, Siddle K (1998) Phosphoinositide 3-kinase: the key switch mechanism in insulin signalling. Biochem J 333: 471-490

13. Holman GD, Kasuga M (1997) From receptor to transporter: insulin signalling to glucose transport. Diabetologia 40: 991-1003

14. Flier JS, Young J, Landsberg L (1980) Familial insulin resistance with acanthosis nigricans, acral hypertrophy, and muscle cramps. N Engl J Med 970-973

15. Dib K, Whitehead JP, Humphreys PJ et al. (1998) Impaired activation of phosphoinositide 3-kinase by insulin in fibroblasts from patients with severe insulin resistance and pseudoacromegaly - A disorder characterized by selective postreceptor insulin resistance. J Clin Invest 101: 1111-1120

16. Kausch C, Bergemann C, Hamann A, Matthaei S (1999) Insulin-mediated pseudoacromegaly in a patient with severe insulin resistance: association of defective insulinstimulated glucose transport with impaired phosphatidylinositol 3-kinase activity in fibroblasts. Exp Clin Endocrinol Diabetes 107: 148-154

17. Otsu M, Hiles I, Gout I et al. (1991) Characterization of 2 $85 \mathrm{kd}$ proteins that associate with receptor tyrosine kinases, middle-T/pp60c-Src complexes, and PI 3-kinase. Cell 65: 91-104

18. Escobedo JA, Navankasattusas S, Kavanaugh WM et al. (1991) cDNA cloning of a novel $85 \mathrm{kd}$ protein that has $\mathrm{SH} 2$ domains and regulates binding of PI 3-kinase to the PDGF $\beta$-receptor. Cell 65: 75-82

19. Skolnik EY, Margolis B, Mohammadi M et a]. (1991) Cloning of PI 3 kinase-associated p85 utilizing a novel method for expression/cloning of target proteins for receptor tyrosine kinases. Cell 65: 83-90
20. Fry MJ, Panayotou G, Dhand R et al. (1992) Purification and characterization of a phosphatidylinositol 3-kinase complex from bovine brain by using phosphopeptide affinity columns. Biochem J 288: 383-393

21. Gout I, Dhand R, Panayotou G et al. (1992) Expression and characterization of the p85 subunit of the phosphatidylinositol 3-kinase complex and a related p85-Beta protein by using the Baculovirus expression system. Biochem J 288: 395-405

22. Pons S, Asano T, Glasheen E et al. (1995) The structure and function of $\mathrm{p} 55^{\mathrm{PIK}}$ reveal a new regulatory subunit for phosphatidylinositol 3-kinase. Mol Cell Biol 15: 4453-4465

23. Inukai K, Anai M, Vanbreda E et al. (1996) A novel 55$\mathrm{kDa}$ regulatory subunit for phosphatidylinositol 3-kinase structurally similar to p55PIK is generated by alternative splicing of the p85-alpha gene. J Biol Chem 271: 53175320

24. Inukai K, Funaki M, Ogihara T et al. (1997) p85a gene generates three isoforrns of regulatory subunit for phosphatidylinositol 3-kinase (PI 3-kinase), p50 $\alpha$, p55 $\alpha$ and p $85 \alpha$, with different PI 3-kinase activity elevating responses to insulin. J Biol Chem 272: 7873-7882

25. Antonetti DA, Algenstaedt P, Kahn CR (1996) Insulin receptor substrate-1 binds two novel splice variants of the regulatory subunit of phosphatidylinositol 3-kinase in muscle and brain. Mol Cell Biol 16: 2195-2203

26. Fruman DA, Cantley LC, Carpenter CL (1996) Structural organization and alternative splicing of the murine phosphoinositide 3-kinase p85 $\alpha$ gene. Genomics 37: 113-121

27. Shepherd PR, Nave BT, Rincon J et al. (1997) Differential regulation of phosphoinositide 3-kinase adapter subunit variants by insulin in human skeletal muscle. JJ Biol Chem 272: 19000-19007

28. Terauchi Y, Tsuji Y, Satoh S et al. (1999) Increased insulin sensitivity and hypoglycaemia in mice lacking the p $85 \alpha$ subunit of phosphoinositide 3-kinase. Nat Genet 21: 230-235

29. Jackson TR, Stephens LR, Hawkins PT (1992) Receptor specificity of growth factor-stimulated synthesis of 3-phosphorylated inositol lipids in Swiss 3T3 cells. J Biol Chem 267: 16627-16636

30. Vadnal RE, Parthasarathy R (1989) The identification of a novel inositol lipid, phosphatidylinositol trisphosphate (PIP3), in rat cerebrum using in vivo techniques. Biochem Biophys Res Commun 163: 995-1001

31. Panayotou G, Gish G, Truong O et al. (1993) Interactions between $\mathrm{SH} 2$ domains and tyrosine-phosphorylated platelet-derived growth factor $\beta$-receptor sequences: analysis of kinetic parameters by a novel biosensor-based approach. Mol Cell Biol 13: 3567-3576

32. Baier LJ, Wiedrich C, Hanson R, Bogardus C (1998) Variant in the regulatory subunit of phosphatidylinositol 3-kinase $(\mathrm{p} 85 \alpha)$-preliminary evidence indicates a potential role of this variant in the acute insulin response and type 2 diabetes in Pima women. Diabetes 47: 973-975

33. Williams DRR, Wareham NJ, Brown DC et al. (1995) Undiaggnosed glucose intolerance in the community - the Isle of Ely Diabetes Project. Diabet Med 12: 30-35

34. Kawanishi M, Tamori Y, Masugi J et al. (1997) Prevalence of a polymorphism of the phosphatidylinositol 3-kinase p $85 \alpha$ regulatory subunit (codon 326 (Met $\rightarrow$ Ile)) in Japanese NIDDM patients. Diabetes Care 20: 1043

35. Bjornholm M, Kawano Y, Lehtihet M, Zierath JR (1997) Insulin receptor substrate-1 phosphorylation and phosphatidylinositol 3-kinase activity in skeletal muscle from NIDDM subjects after in vivo insulin stimulation. Diabetes 46: $524-527$ 
36. Goodyear LJ, Giorgino F, Sherman LA et al. (1995) Insulin receptor phosphorylation, insulin receptor substrate-phosphorylation, and phosphatidylinositol 3-kinase activity are decreased in intact skeletal muscle strips from obese subjects. J Clin Invest 95: 2195-2204

37. Rondinone CM, Wang LM, Lonroth P et al. (1997) Insulin receptor substrate (IRS) 1 is reduced and IRS-2 is the main docking protein for phosphatidylinositol 3-kinase in adipocytes from subjects with non-insulin-dependent diabetes mellitus. Proc Natl Acad Sci USA 94: 4171-4175

38. Hansen T, Andersen CB, Echwald SM et al. (1997) Identification of a amino acid polymorphism in the p85 $\alpha$ regulatory subunit of phosphatidylinositol 3-kinase. Diabetes 46 : 494-501

39. Yu JH, Wjasow C, Backer JM (1998) Regulation of the p85/p110 $\alpha$ phosphatidylinositol 3'-kinase - Distinct roles for the N-terminal and C-terminal SH2 domains. J Biol Chem 273: 30199-30203

40. Nolte R, Eck M, Schlessinger J, Shoelson S, Harrison S (1996) Crystal structure of the PI 3-kinase p85 amino-terminal SH2 domain and its phosphopeptide complexes. Nat Struct Biol 3: 364-373

41. Herbst A, Andrews G, Contillo L et al. (1994) Potent activation of phosphatidylinositol 3'-kinasc by simple phosphotyrosine peptides derived from insulin receptor substrate-1 containing 2 YMXM motifs for binding SH2 domains. Biochemistry 33: 9376-9381

42. Carpenter CL, Auger KR, Chanudhuri M et al. (1993) Phosphoinositide 3-kinase is activated by phosphopeptides that bind to the $\mathrm{SH} 2$ domains of the $85-\mathrm{kD}$ a subunit. J Biol Chem 268: 9478-9483
43. Rordorf-Nikolic T, Van Horn DJ, Chen DX, White MF, Backer JM (1995) Regulation of phosphatidylinositol 3'-kinase by tyrosyl phosphoproteins - full activation requires occupancy of both $\mathrm{SH} 2$ domains in the $85-\mathrm{kDa}$ regulatory subunit. J Biol Chem 270: 3662-3666

44. O'Rahilly S (1997) Diabetes in midlife: planting genetic time bombs. Nat Med 3: 1080-1081

45. Stenbit AE, Tsao TS, Li J et al. (1997) GLUT4 heterozygous knockout mice develop muscle insulin resistance and diabetes. Nat Med 3: 1096-1101

46. Bruning JC,Winnay J, Bonner-Weir S et al.(1997) Development of a novel polygenic model of NIDDM in mice heterozygous for IR and IRS-1 null alleles. Cell 88: 561-572

47. Whitehead JP, Humphreys P, Krook A et al.(1998) Molecular scanning of the insulin receptor substrate 1 gene in subjects with severe insulin resistance -detection and functional analysis of a naturally occurring mutation in a YMXM motif. Diabetes 47: 837-839

48. Almind K, Bjorbaek C, Vestergaard H, Hansen T, Pedersen O (1993) Amino acid polymorphisms of insulin receptor substrate-1 in non-insulin dependent diabetes mellitus. Lancet 342: 828-832

49. Almind K, Inoue G, Pedersen O, Kahn CR (1996) A common amino acid polymorphism in insulin receptor substrate-1 causes impaired insulin signalling. J Clin Invest 97: 2569-2575

50. Yoshimura R, Araki E, Ura S et al. (1997) Impact of natural IRS-1 mutations on insulin signals - mutations of IRS1 in the PTB domain and near $\mathrm{SH} 2$ protein binding sites result in impaired function at different steps of IRS-1 signaling. Diabetes 46: 929-936 